\title{
Library Experiential Marketing Strategy as a Means of Increasing Library Satisfaction in the Use of E-Resources During the Covid-19 Pandemic
}

\author{
Endang Fatmawati \\ Diponegoro University, Semarang, Central Java, Indonesia \\ Email: endangfatmawati@live.undip.ac.id
}

\begin{abstract}
This study aims to analyze the effects of library experiential marketing strategies on user satisfaction levels during the Covid-19 pandemic, using a quantitative approach. Data were collected through observation, questionnaires, and reviews of related literature. Based on the results obtained, experiential marketing is a suitable marketing concept for libraries. This strategy is bound to aid libraries in providing pleasant and unforgettable services. The priority of experiential marketing strategy during the Covid-19 pandemic is to observe the responses of users by testing the variables of sense, feel, think, act, and relate/linkage. These five independent variables have a positive and significant effect on user satisfaction, indicating the potential for libraries to improve user experience by connecting through reallife users. In conclusion, experiential marketing strategies can provide positive experiences for users and, consequently, improve the interest in optimizing the use of electronic information resources, even during the Covid-19 pandemic.
\end{abstract}

Keywords: Experiential Marketing, User Experience, Covid-19, User Satisfaction, Library Online Service.

\section{A. INTRODUCTION}

The development of increasingly sophisticated technology is bound to provide diverse experiences for users. Therefore, the experiential marketing strategy ought to be adopted in marketing library services. The increasingly rapid technological revolution certainly aid the quick spread of information about the benefits of a library through various media. However, libraries and librarians of the Faculty of Economics and Business, Diponegoro University, need to build an assertive relationship with users in each interaction. An assertive librarian aims to build emotional closeness in the provision of services to users, and this is a good strategy to increase customer loyalty.

During the Covid-19 pandemic, the Library of the Faculty of Economics and Business conducted a series of workshop series \#1 to \#4, as well as regular socialization at several levels. However, these activities have had little significance in improving the satisfaction of users with the library services. Therefore, an experiential marketing approach ought to be implemented to solve these problems.

Library services have been impacted significantly by the Covid-19 pandemic, for instance, certain services that were originally carried out physically are now being conducted online. As an initial observation, interviews were conducted with 
several students who rarely visited the library. The question asked was "Why do you rarely visit the library?" Their answers were astonishing because the majority of respondents considered the library staff to be unfriendly, unprofessional, and unresponsive, while the rest disclosed other unpleasant reasons. This implies these respondents have had poor and traumatizing experiences with library services.

Based on existing literature, there are no known studies on experiential marketing approach with library objects, especially during the Covid-19 pandemic. Therefore, this study is necessary to discover the experiential marketing strategies implemented to create good user experiences. This study is expected to aid library management in increasing the satisfaction of library users (users) with the electronic information resource services provided. Based on the background of this problem statement, this study aims to perform an experiential marketing analysis to measure user satisfaction in the Library of the Faculty of Economics and Business, Diponegoro University.

This study aims to analyze the variables of sense, feel, think, act, and relate effects in the interaction with librarians of the Undip FEB Library, as well as the effect of these variables on user satisfaction in library services. The theoretical benefits of this study's findings are expected to serve as reference material for future related studies. This complex study is also expected to provide benefits for the development of science and serves as a further reference, especially for librarians interested in learning about experiential marketing analysis on user satisfaction.

\section{B. LITERATURE REVIEW}

The marketing of library services is an essential for library. Gupta, et al. (2006) explained that working librarians as well as future librarians to understand the important issues related to the marketing of library services. In contextualizing the essence of experiential marketing in libraries, the first step is the question of how librarians create positive perceptions in the minds of users, particularly the efforts to build lasting relationships with users.

The term "experiential" was derived from the word "experience", which was defined by Schmitt (1999b) as a private event that occurs in response to certain stimulation. This indicates the experiential marketing strategy aims to simulate intense positive life experiences, which tend to be unforgettable. According to McCole (2004), experiential marketing is an effort to develop marketing concepts in the face of market changes.

Company's brands are not only mere identifiers facilitating the experience, but rich sources of sensory, affective, and cognitive associations that result memorable and rewarding brand experiences (Schmitt, 1999a). In library use, the experience of the user shows a response that occurs due to a stimulus. Each user's experience is personal, therefore, the librarian can create a memorable experience. A pleasant experience is assured to give users a positive perception of the library. This form of marketing communication where emotions are involved is in line with the experiential marketing approach. A report by Bernardin and Russel (1993) highlighted size, 
namely quality, quantity, timeliness, cost-effectiveness, need for supervision, and interpersonal impact as important factors in this strategy.

In library services, there is an important term known as "moments of truth", which refers to the most decisive moment when the user chooses whether to be more diligent in visiting, visit only when necessary, or exhibit loyalty by visiting often and inviting other users. The value of the relationship between users and libraries is determined based on 3 aspects: the librarians, library service products, and service processes. Smilansky (2018) disclosed the experiential marketing approach is bound to focus on real-time two-way interaction and creating a good brand experience to obtain a significantly stronger service-user bonding process.

Even if the library is not profit-oriented, in line with the current trend of open access, a library that neglects continuously improving services is inevitable to become devoid of visitors with time. Subsequently, access to information ought not to be restricted to physical visits, but ought to be possible from anywhere and at any time. To understand the experiential marketing philosophy and improve user satisfaction with library services, Siess (2003) recommended a tip to ensure all the reviews from users are positive.

Kotler \& Keller (2012) defined satisfaction as the level of a person's feelings after comparing the perceived results with the desired expectations. Therefore, experiential marketing in libraries ought to be developed in a concept that can integrate elements of emotion, logic, and general thought processes from librarians to connect with the conditions of users. Duke, MacDonald, \& Trimble (2009) emphasizes collaboration between marketing students and the library. The impact of the working relationship that especially in light of past experiences.

This strategy is based on the real experiences of users with all library services and is consequently, expected to aid libraries in selecting the appropriate approach to achieve desired goals. The following strategies have been formulated to increase user creativity.

1. Surprise

Surprising experiences tend to create a deep and unforgettable emotional impression. Furthermore, positive surprises are interpreted more comprehensively, for instance, providing users with better services than expected by increasing the usefulness and enjoyability of the services provided is assured to achieve customer satisfaction.

2. Intrigue

Librarians are fostered to provide a captivating stimulus by arousing the user's curiosity.

3. Provocation

This is expected to help facilitate discussions between librarians and users, consequently, establishing emotionally-friendly interpersonal relationships.

In library services, marketing strategies are much more than just promotion and public relations. According to Pfeil (2005), this is because specific planning, implementation, and evaluation are required. The outreach library covers all the 
qualities of marketing, fulfills the elements of each program, reaches users, and disseminates information, through the "IDEA" strategy, which is an acronym for identity need, design programs, evaluate service, and add new programs.

Doucett (2008) highlighted several important elements in marketing strategy, including, setting goals for library marketing, identifying users (segmenting), defining the target market (targeting), creating a brand (branding), and conducting user reviews to test assumptions about the relevance of the library's existence. Meanwhile, Wallace (2004) reported the following five key elements.

1. The study, to determine the goals, needs, desires, level of user satisfaction by collecting relevant data.

2. Planning, to develop library methods and services.

3. Strategy, to implement effective methods of providing services.

4. Communication, to build awareness and convey the value offered.

5. Evaluation, to monitor effectiveness.

To understand the concept of experiential marketing and its concept, one must first understand Strategic Experience Modules (SEMs) and Experience Providers (ExPros), which are the focus of this strategy. The indicators in SEMs are given below.

1. Sense refers to a type of experience perceived through the eyes, mouth, skin, tongue, or nose.

2. Feeling refers to an experience that appears to touch the emotions of consumers to create an effective experience.

3. Thinking refers to a type of experience that aims to create cognitive, problemsolving skills by inviting users to think creatively.

4. Action refers to a type of experience that aims to influence behavior, lifestyle, and interaction with users.

5. A relationship is a type of experience that aims to influence users by combining all aspects of sense, feel, think, act, and focusing on creating positive perceptions in the eyes of users.

Meanwhile, service with Experience Providers (ExPros) is a component that allows memorable experiences to be formed in the minds of users. The ExPros indicators are outlined below.

1. Communication, for instance, verbal and written interactions between librarians and users, for instance, public relations, advertising.

2. Library visual identity, for instance, the library's logo, vision and mission, building color/paint, and symbols.

3. The presence of library products, for instance, the results of information repackaging, bibliography, and leaflets, as well as the list of the latest collections.

4. A form of collaboration between two or more brands to use power simultaneously for a specific purpose (Co-branding), for instance, displaying Indonesian reading ambassadors with posters inviting "Let's Read", as well as sponsorship of activities. 
5. The spatial environment of the library, for instance, interior design, spatial planning.

6. Websites and electronic media, for instance, library site display, CD-ROM, LAN network, wifi, co-working space.

7. The library staff, meaning the librarians who interact with users in the provision of library services.

Literature on experiences provides a through understanding of internal, psychological, cultural, or environmental factors shaping an experience (Verhoef, et al., 2009; Yakhlef, 2015). Some libraries advertised marketing librarian positions with responsibilities such as branding and social networking (Okamato \& Polger, 2012). Based on the report by Schmitt (1999b), the characteristics of experiential marketing in library services are given below.

1. Focus and prioritize user experiences related to the five senses, feelings, and thoughts. An experience occurs as a meeting, undergoing, or situation which provides sensory, emotional, cognitive, behavioral, and relational values that replace functional values.

2. Pay attention to the situation when providing services, for instance, prioritize spatial planning, types of services provided, and the existing facilities. Based on previous studies, users do not assess a library based on the facility alone, but also from the experience gained while accessing information in the library.

3. Realize that users have rational and emotional thoughts. The user must not be considered from the rational side but also the emotional side. Therefore, librarians are expected to treat users not as rational decision-makers alone but also aim for users to be entertained, stimulated, emotionally influenced, and creatively challenged.

4. Use of technologically advanced methods and devices. This means that the methods and tools for measuring user experience ought to depend more on the object to be measured or refer to each occurrence, rather than using the regular standard.

Smilansky (2018) recommended the BETTER model in experiential marketing, which is an acronym for B (Brand personality), E (Emotional connection), $\mathrm{T}$ (Target audience), T (Two-way interaction), E (Exponential element), and R (reach). Another suitable strategy is the buzz marketing breakthrough or Word-of-Mouth (WOM) approach which refers to the delivery of information from person to person through word of mouth. Therefore, libraries ought to strive to provide users with satisfactory services. A study by Dowd (2010: 3) reported WOM marketing will always have a strong and fast influence as a driver in today's marketing. This is also in line with the report by Scilken in Deitch (2002) and Siess (2003), where publicity with WOM was disclosed to be the most important factor for librarians.

Research related to library marketing to improve library services has been carried out (Rowley, 1995; Mohamedali, 1999; Spalding \& Wang, 2006; Muzvondiwa \& Marutha, 2021). Research on library marketing conducted was essential for creating a marketing program relevant to library customers (MacArthur, 2014). According to 
Schmitt (1999b), there are several benefits of experiential marking in improving user satisfaction. These benefits are outlined below:

1. Reviving a declining library brand: In cases of brand decline, for instance, after a library experiences a crisis of trust in the eyes of users due to poor librarian services, experiential marketing can help revive trust in the library.

2. Differentiate library service products from other libraries: Every library is characterized by unique information products, and experiential marketing helps to distinguish each library product from the other.

3. Creating a corporate image and identity for a library: The experiential marketing approach will create a positive image and identity of a library.

4. Promoting innovations: To improve user satisfaction, libraries require certain strategies to increase user satisfaction, including experiential marketing, which is bound to promote the innovations created by libraries.

5. Increasing customer loyalty: Experiential marketing is used to induce product or service trial, purchase, and, most importantly, loyal consumption, among customers.

The following hypotheses were tested in this study.

1. $\mathrm{H}_{1}$ : The higher the influence of sense, the higher the satisfaction of the users in the Undip FEB Library.

2. $\mathrm{H}_{2}$ : The higher the effect of feel, the higher the satisfaction of the users in the Undip FEB Library.

3. $\mathrm{H}_{3}$ : The higher the influence of think, the higher the satisfaction of the users in the Undip FEB Library.

4. $\mathrm{H}_{4}$ : The higher the effect of the act, the higher the satisfaction of the users in the Undip FEB Library.

5. $\mathrm{H}_{5}$ : The higher the relate effect, the higher the satisfaction of the users in the Undip FEB Library.

\section{METHOD}

The independent variables $(X)$ in this study are $X 1=$ sense, $X 2=$ feel, $X 3=$ think, $\mathrm{X} 4=$ act, and $\mathrm{X} 5=$ relate, while the dependent variable $(\mathrm{Y})$ is user satisfaction. The study population is students who are registered users of the Undip FEB Library (980 active students). However, the sample used is the users (students) who visit the FEB Undip Library, which is $10 \%$ of the total population with a judgment sampling system of 98 students. The main inclusive criteria for the sample selection is the intensity or frequency of active visits to the Undip FEB Library. Data were collected through observation, questionnaires, and reviews of related literature. Subsequently, the data were subjected to multiple linear regression analysis to test the effect of the five variables in experiential marketing on the variable of user satisfaction.

\section{RESULTS AND DISCUSSION}

Marketing of library services and resources has a great impact on their usage. Based on the results, the coefficient of determination (adjusted $\mathrm{R}^{2}$ ) obtained is 0.508 , 
meaning $50.8 \%$ of user satisfaction can be explained by experiential marketing variables of sense, feel, think, act, and relate. Therefore, $49.2 \%$ of user satisfaction can be explained from other indicators besides the five variables. Furthermore, for all indicators used to measure the variables, the correlation coefficient was above $r$ table $=0.198$ ( $\mathrm{r}$ table value for $\mathrm{n}=98$ ). This indicated all the indicators of the experiential marketing questionnaire are valid. Meanwhile, the reliability test showed all variables have a fairly large Alpha coefficient, which is above 0.60 . Therefore, all the concepts of measuring each variable from the questionnaire are suitable and reliable measuring tools.

Subsequently, a classical assumption test which comprised a normality test, multicollinearity test, and heteroscedasticity test, was performed. The normality test was carried out on the regression residuals, using the P-P Plot graph. According to the linear regression analysis with a normal P-P plot of the residual error of the regression model, a normal graph distribution was obtained. Normal data refers to data that forms points spread close to the diagonal line. Meanwhile, multicollinearity was determined from the high Variance Inflation Factor (VIF) value on the independent variables of a regression model. Based on the results, the VIF values of all independent variables were below 10, indicating the variables in experiential marketing do not show any symptoms of multicollinearity in the regression model. The heteroscedasticity test was performed to determine whether the regression model contained an inequality of residual variance. In cases where the residual variance from one observation to another observation remains, the regression model is said to possess homoscedasticity, however, in cases where the variance is different, the model is said to possess heteroscedasticity. The scatterplots show the points are randomly spread above and below the number 0 and the Y-axis. Thus, the regression model possesses no heteroscedasticity and is, therefore, feasible for conducting the test.

Marketing today spreads its wings within library services and is described in new category such as experiential marketing (Gupta, 2006). NN (2018) offers a stepby-step plan for using all marketing and communication media to create immersive experiences that facilitate brand engagement and brand experiences in consumers.

The purpose of experiential marketing is to build harmonious interpersonal relationships between librarians and users, as well as to measure the users' response to library services based on the level of emotional and rational response. This marketing strategy is a service activity provided by a librarian to anticipate, manage, and achieve user satisfaction based on an exchange process through various personal events that occur as a response or several stimuli.

To answer the proposed hypothesis, a multiple linear regression analysis model was created with experiential marketing variables on user satisfaction and linear regression analysis of the influence of the five variables in experiential marketing. This study paid close attention to the level of significance (on Standardized Coefficients) to obtain accurate results from the analysis based on the quantitative data processed. This is crucial because even a minute difference in value will significantly 
influence the results of the analysis or interpretation. The results of the regression test are shown in the multiple linear regression equation below.

$$
\mathrm{Y}=0.183 \mathrm{X} 1+0.251 \mathrm{X} 2+0.285 \mathrm{X} 3+0.204 \mathrm{X} 4+0.215 \mathrm{X} 5
$$

Based on the model, the regression coefficient for the sense indicator has a significant positive effect of 0.183 , while the feel indicator has a significant positive effect of 0.251 on user satisfaction. Furthermore, the think indicator has a significant positive effect of 0.285 and the act indicator has a significant positive effect of 0.204 , while the relationship or relate indicator has a significant positive effect of 0.215 on the user satisfaction variable. The analysis performed using the standardized coefficient value of the multiple linear regression model showed the think variable has the largest regression coefficient value, meaning this variable is the indicator with the most dominant influence on user satisfaction.

An $F$ test was carried out to evaluate the effect of independent variables together (simultaneously) on the dependent variable. According to the statistical calculation performed using SPSS, the F value was 20.897 with a significance level of 0.000. The significance value of $\mathrm{F}$ is below 0.05 , therefore, the hypothesis which states the five independent variables have a significant influence on user satisfaction is acceptable. Based on these results, the following discussion was formulated.

\section{Sense Variable on User Satisfaction}

Certain aspects are perceivable from library services are captured by the five senses to create a sensory experience for the user through sight, sound, touch, taste, and smell. Consequently, the user's feeling arises through the experience of the five senses which function to differentiate the user's motivation.

For instance, a comfortable library room, an attractive interior design, a pleasant layout, adequate facilities, high-quality service products, as well as the display of a meaningful library logo. An increase in the quality of the library's aesthetics and services is expected to multiply the number of new and returning visitors. Spalding \& Wang (2006) that the library is more successful in gaining visibility and support for its efforts, and making the best use of the service available to them to meet their academic and research goals.

The results obtained for the sense variable showed the regression coefficient has a positive direction, with a $t$ value of 2.455 and a significance level of 0.016 . The significance level obtained for this variable is below the limit of 0.05 , therefore, the sense variable was concluded to have a positive and significant effect on student satisfaction. This means Hypothesis 1 is also acceptable.

As a competent educational institution in the vision and mission of higher education, the FEB Undip Library provides access to information sources or adequate service facilities, which directly influences the quality of services provided. The five senses are an important factor for a first-time user of the Undip FEB Library's services. Therefore, to successfully implement an experiential marketing approach, the library must seek to involve as many senses as possible.

The existence of a positive perception indicates the user had a positive experience, and this is a very important factor in the success of library services. 
Positive experiences can only be embedded in the minds of users when librarians realize the value of experience and successfully apply experiential marketing while interacting with visitors. This is because the users feel impressed and have a pleasant experience while interacting with librarians. The librarian can act liaison with the academic community. Silver \& Trott (2014) mentioned that each librarian liaison needs to determine the most cost-effective outreach strategies to achieve both efficiency and effectiveness for the library, for their clientele, and for their own professional satisfaction.

\section{Feel Variable on User Satisfaction}

Experiential marketing is one of the marketing concepts which provides users with unique experiences, to create a positive and impressive impact. This is easily achieved by librarians with the ability to appeal to the emotions of users. The variable of feel relates to the user's mood and emotions, which can be expressed as pleasure, pride, or even as a sense of comfort when visiting the library. In this case, the user's feelings are generated through emotional experiences to create an affective experience. For instance, librarians are promoted to be friendly and polite to all users, as well as to always aim for optimum user satisfaction.

According to the results obtained for the feel variable, the regression coefficient value has a positive direction, with a t value of 3.281 and a significance level of 0.001 . The significance value of 0.001 obtained for this variable is below the limit of 0.05 . Therefore, hypothesis 2 which states feel has a positive and significant effect on student satisfaction is acceptable. This indicated an improvement in the feel provided by the Undip FEB Library to visitors, is guaranteed to increase user satisfaction.

Subsequently, this condition is related to the importance of feeling as an important component in library services. Providing timely and appropriate library service items are bound to reflect the success of the Undip FEB Library staff in providing satisfaction to the users. This will give a good perception of the services provided, meaning the user's expectations are met.

During the Covid-19mpandemic, the Undip FEB Library the Covid-19 switched its operations to online helpdesk-based user service. Furthermore, as the library's main assets, librarians have experienced pressure to be more digitally literate. Concerning the five senses, experiential marketing seeks to connect with customers through inspiring thoughts about comfort and pleasure, as well as practicality.

\section{Think Variable on User Satisfaction}

This variable stimulates creativity, intellectual abilities, and creates cognitive thoughts to awaken the mind to build a solutive mindset through personal experiences. Librarians have the ability to improve creative thinking in users and obtain positive responses to library services. For example, providing users with opportunities to submit complaints/suggestions/criticisms as input for the library, and providing services that exceed user expectations, as well as a good understanding of the library's functions.

Based on the results, the thought pattern variable (think) has a regression coefficient with a positive direction as well as a t value of 3.582 and a significance level 
of 0.001 . This significance level is below the set limit of 0.05 , therefore, hypothesis 3 which states that mindset (think) has a positive and significant effect on user satisfaction, is acceptable.

These results indicate improved responsiveness variable of the FEB Undip Library staff is bound to increase user satisfaction. The responsibility of librarians while interacting with users determines the reaction of the user. Therefore, officers with positive towards student complaints give the users a sense of confidence of an impending good service.

Regarding publicity, a librarian must be able to foster good public relations by being polite and friendly to visitors. This is conducted to increase the number of new and returning visitors. Therefore, librarians must be confident in exhibiting the advantages of their library visually. For example, a library website that is always updated with information will constantly be visited by users. Similarly, the use of visually attractive guides and signs in the library is bound to give users a unique and pleasant sensation. The easiest way to elevate customer satisfaction and consequently, boost the number of new and returning visitors, is to appeal to the emotions of users.

Experiential marketing does not only show users the features and benefits of a library service product but also provides a positive sensation and experience. These conditions form the basis for user satisfaction with the library's services. Experiential marketing has begun to shift the traditional marketing approach which revolves around Product, Price, Place, as well as Promotion (4Ps) and relies only on features and benefits. The features of a product are the characteristics that complement the basic functions of a product, while the benefits refer to the consumer's desired performance characteristics.

4. Act Variables on User Satisfaction

The act variable relates to real behavior by increasing the user's physical experience. This variable also creates experiences involving the user's body, lifestyle, and interactions. These habits, for instance, the completeness of library collections, courteous interactions between librarians and users, availability of information, and access to adequate digital facilities, as well as easily accessible library locations will then form the user's perception of the experience of the service rendered.

The results obtained for the habit variable (act) showed the regression coefficient has a positive direction, with a $t$ value of 2.595 and a significance level of 0.011 . The significance value of this variable is below the limit of 0.05 . Therefore, the variable of habit (act) has a positive and significant effect on student satisfaction. This means hypothesis 4 is acceptable.

An increase in the positive acts of the Undip FEB Library towards students is performed to promote user satisfaction. The FEB Undip Library is therefore recommended to provide students with a habit (act) for each service or complaint to be handled properly. Every student desires to be treated well and rendered excellent serviced, therefore, these acts from the library's service employees are conducted to escalate user satisfaction. Feldman \& Rich (2015) confirmed that library professionals 
must become format-agnostic information experts, providing equitable access to physical material, internet-connected devices, and online content.

Library users are more likely to believe more in the word of mouth marketing techniques, compared to formal library promotions. Students tend to believe more when friends say the Undip FEB Library is comfortable, compared to a brochure where the library's facilities are described. Therefore, providing quality services that result in user satisfaction is accomplished to improve the library's publicity.

5. Variables Relate to User Satisfaction

Relate or linkage stimulates the formation of relationships with fellow users. This helps to create a more powerful experience by exceeding the user's personal feelings while fostering new relationships through effective communication. This variable is related to the other four experiential marketing indicators: the five senses, feelings, ways of thinking, and habits. For instance, direct contact with other users, positive reviews, well-developed family culture, as well as library services are in line with the expectations of the users. Skandalis, Byrom, \& Banister (2018) have described outline tehe theoretical implications for the changing nature of extraordinary consumption experiences, in light of post-postmodern consumer culture.

Based on the results obtained for the related variable, the regression coefficient has a positive direction, with a $t$ value of 2.672 and a significance level of 0.009 . This variable has a significance level below the limit of 0.05 , therefore, hypothesis 5 which states that the variable of relationship has a positive and significant effect on student satisfaction, is acceptable.

Under normal circumstances, everyone who is treated with respect and care develops a genuine positive emotion towards the person who treats them in such a manner. Similarly, students who are treated with respect and care by the FEB Undip Librarians are bound to give positive reviews about the library.

According to Daft et al., (2010), librarians are expected to possess a genuine determination to improve their interactions with library users, and this change begins from the stages of how to prepare, accept, to make a commitment. Xiangjun (2009) explained the library set out its experiential marketing strategies and designing the topic of experiential marketing.

Therefore, every Undip FEB Library officer must constantly improve his or her competence. Also, each library must completely understand its user characteristic, to obtain an idea of the users' needs. Efforts to optimize experiential marketing by understanding the trends in users' thoughts, feelings, and expectations, will enable librarians to develop ideas on how to provide users with information on subscribed e-resources and persuade users to optimize the use of these e-resources during the Covid-19 pandemic.

\section{E. CONCLUSION}

Library experiential marketing strategies ought to be implemented to optimize the use of electronic information resources during the Covid-19 pandemic. The focus of implementing these strategies at the Undip FEB Library is to create user experiences 
through reason, feeling, thinking, acting, and relating, to build an emotional bond between the FEB Undip Library and its users through the creation of experiences. Based on this study's results, the experiential marketing variable with the greatest influence on user satisfaction is the think variable which a larger regression coefficient $(\beta)$ of 0.285 , followed by the variables of feel, relate, act, and sense, with regression coefficient values $(\beta)$ of $0.251,0.215,0.204$, and 0.183 , respectively.

\section{REFERENCES}

1. Daft, R. L., et al. (2010). Organization Theory Design. 9 ${ }^{\text {th }}$ Edition. United Kingdom: South-Western, Cengage Learning.

2. Doucett, E. (2008). Creating Your Library Brand: Communicating Your Relevance and Value to Your Patrons. Chicago: American Library Association.

3. Dowd, N., et al. (2010). Bited-Sized Marketing: Realistic Solutions for The Overworked Librarian. Chicago: American Library Association.

4. Duke, L.M., MacDonald, J.B., \& Trimble, C.S. (2009). Collaboration between Marketing Students and the Library: An Experiential Learning Project to Promote Reference Services. College \& Research Libraries, 70(2), 109-121.

5. Feldman, S., \& Rich, H. (2015). Transforming the Library Profession. American Libraries, 36-39.

6. Gupta, D.K., et al. (2006). Marketing Library and Information Services: International Perspectives. Germany: K.G. Saur.

7. Kotler, P. \& Keller, K. (2012). Marketing Management. $14^{\text {th }}$ ed. New Jersey: Prentice Hall.

8. MacArthur, E. (2014). More Than a Libray: An Outline for an Integrated Marketing Communication Campaign. Thesis. Master of Science. Departement of Communication. College of Liberal Arts.

9. McCole, P. (2004). Refocusing Marketing to Reflect Practice: The Changing Role of Marketing for Business. Marketing Intelligence E Planning, 22 (5), pp. 531-539.

10. Mohamedali, O.N. (1999). Marketing for Information Professionals in The Caribbean. New Library World, 100(1152), 307-314.

11. Muzvondiwa, I. \& Marutha, N.S. (2021). Framework for Improving Usage of Library Services and Resources in The Private Higher Education in South Africa. Digital Library Perspectives, 2059-5816.

12. NN. (2018). Experiential Marketing: A Practical Guide to Interactive Brand Experiences. $2^{\text {nd }}$ Edition. Beaverton: Ringgold Inc.

13. Okamato, K. \& Polger, M.A. (2012). Off to Market We Go: A Content Analysis of Marketing and Promotion Skills in Academic Librarian Job Ads. Library Leadership $\mathcal{E}$ Management, 26, 1-20.

14. Pfeil, A.B. (2005). Going Places with Youth Outreach: Smart Marketing Strategies for Your Library. Chicago: American Library Association.

15. Rowley, J.E. (1995). From Storekeeper to Salesman: Implementing The Marketing Concept in Libraries. Library Review, 44(1), 24-35. 
16. Schmitt, B.H. (1999a). Experiential Marketing. Journal of Marketing Management, 15(11-3), 53-67.

17. Schmitt, B.H. (1999b). Experiential Marketing: How to Get Sense, Feel, Think, Act, and Relate to Your Company and Brands. New York: The Free Press.

18. Siess, J.A. (2003). The Visible Librarian: Asserting Your Value with Marketing and Advocacy. Chicago: American Library Association.

19. Silver, I.D \& Trott, B. (2014). Outreach Activities for Librarian Liaisons. Reference $\mathcal{E}$ User Service Quarterly, 54(2), 8-14.

20. Skandalis, A., Byrom, J., \& Banister, E. (2018). Experiential Marketing and The Changing Nature of Extraordinary Experiences in Post-Postmodern Consumer Culture. Journal of Business Research, 97, 43-50.

21. Smilansky, S. (2018). Experiential Marketing: A Practical Guide to Interactive Brand Experiences. $2^{\text {nd }}$ Edition. New York: Kogan Page.

22. Spalding, H.H. \& Wang, J. (2006). The Challenges and Opportunities of Marketing Academic Libraries in The USA: Experiences of US Academic Libraries with Global Application. Library Management, 27(6/7), 494-504.

23. Verhoef, P.C., et al. (2009). Customer Experience Creation: Determinats, Dynamics and Management Strategies. Journal of Retailing, 85(1), 31-41.

24. Wallace, L.K. (2004). Libraries, Mission and, E Marketing: Writing Mission Statements That Work. Chicago: American Library Association.

25. Xiangjun, F. (2009). Analysis on Experiential Marketing Strategy of Library Based on User Information Behavior. Library Work and Study. Department of Information Resource Management, Nankai University, Tianjin.

26. Yakhlef, A. (2015). Customer Experience Within Retail Environments: An Embodied, Spatial Approach. Marketing Theory, 15(4), 545-564. 